\title{
ĐÁNH GIÁ MỨC Độ RỦI RO VÙNG BIỀN VEN BỜ KHU VỤCC MỸ GIANG - HÒN ĐỎ - BÃI CỎ THUỘC XÃ NINH PHƯỚC, NINH HÒA, KHÁNH HÒ̀A
}

\author{
Nguyễn Trâm Anh ${ }^{1}$, Nguyễn Kỳ Phùng²
}

Tóm tắt: Đánh giá rủi ro môi trường là việc lượng hóa khả năng gây hại đến môi truờng của các nhân tố nhân sinh, tù đó có thể giảm thiểu, ngăn ngùa rủi ro môi trường có thể xảy ra tại khu vực nghiên cứu để tối ư về chi phí xủ lý hoặc bồi thường thiệt hại gây ra. Đánh giá rủi ro môi truờng nước biển ven bò̀ khu vực khu vực Mỹ Giang - Hòn Đỏ - Bãi Cỏ nhằm xác định được các tác nhân tiềm tàng thông qua các giá trị chất lương nước biển đã được lấy mẫu và phân tích - mà hầu hết các thông số chất lượng nước biển này đều nằm trong giới hạn cho phép của QCVN 10:2008/BTNMT $\left(^{*}\right)$ nhu: chất dinh duõng $\left(\mathrm{NH}_{3,4-\mathrm{N}}, \mathrm{NO}_{3}-\mathrm{N}, \mathrm{PO}_{4}-\mathrm{P}\right)$ và chất rắn lo lửng (TSS). Các kết quả tính toán hệ số rủi ro của chất dinh duõng $\left(\mathrm{NH}_{3,4}-\mathrm{N}\right)$; $\left(\mathrm{NO}_{3}-\mathrm{N}\right)$ và $\left(\mathrm{PO}_{4}-\mathrm{P}\right)$ tại thời điểm lấy mẫu, tính toán sau 1 đến 15 ngày lần lươt dao động tù (0,45-0,33); (0,80-0,70) và (0,27-0,14); của chất rắn lo lửng (TSS) là $(0,14-0,12)$ cho thấy tại thời điểm khảo sát khu vục nghiên cứu vẫn nằm trong giới hạn an toàn về mặt môi trường.

Từ khóa: Chất lượng nước biển ven bò̀, đánh giá rủi ro, Mỹ Giang - Hòn Đỏ - Bãi Cỏ.

Ban Biên tập nhận bài: 18/10/2018 Ngày phản biện xong: 05/12/2018 Ngày đăng bài: 25/01/2019

\section{Mở đầu}

Khu vực Mỹ Giang - Hòn Đỏ - Bãi Cỏ thuộc xã Ninh Phước, huyện Ninh Hòa, tỉnh Khánh Hòa là nơi có nhiều dự án đã đang hoạt động như nhà máy xi măng Hòn Khói; nhà máy sửa chữa tàu biển Hyndai Vinashin; dự án khai thác, chế biến đá và đất san lấp làm vật liệu xây dựng của công ty Cổ phần du lịch dịch vụ Vân Phong; khu du lịch Dốc Lếch, khu vực nuôi trồng thủy sản Hòn Đỏ...và trong thời gian tới, tổ hợp các nhà máy nhiệt điện Vân Phong sẽ được xây dựng và đi vào hoạt động tại khu vực này.

Tác động của các nhà máy này đến vùng biển ven bờ là điều chắc chắn (ô nhiễm nhiệt, ô nhiễm dầu, tác động đến môi trường biển và các hệ sinh thái ven bờ...). Dưới tác động của dòng chảy, sóng, thủy triều sẽ mang chất ô nhiễm từ nơi này đến nơi khác, cũng như làm tăng khả năng rủi ro môi trường khu vực ven bờ xã Ninh Phước, thị xã Ninh Hòa.

\footnotetext{
${ }^{1}$ Trường Đại học Tài nguyên và Môi trường Tp.HCM

${ }^{2}$ Sở Khoa hoc và Công nghẹ Tp.HCM

Email:ngtanh@hcmunre.edu.vn; ky-

phungng@gmail.com
}

Vì vậy, việc lấy mẫu phân tích để đánh giá chất lượng môi trường nền tại khu vực nghiên cứu, từ đó có thể tính toán các hệ số rủi ro về chất lượng môi trường nước ven bờ là hết sức cần thiết. Đây là, căn cứ ban đầu để đánh giá các mức độ rủi ro tăng hay giảm hoặc diễn biến của môi trường trong tương lai khi mà các hoạt động nhân sinh ngày một dầy đặc hơn.

\section{Phương pháp nghiên cứu}

\subsection{Thu mẫu}

Kỹ thuật lấy mẫu nước biển: TCVN 5995:1995 (ISO 5667-9:1987); Thiết bị: Bothomet plastic plastic và được chứa trong các bình PE đã được xử lý và tráng bằng nước mẫu hai lần.

Mẫu được thu hai đợt (tháng 4 và tháng 10/2013) tại tầng mặt (cách mặt nước $50 \mathrm{~cm}$ ) và tầng đáy (cách đáy $100 \mathrm{~cm}$ ) tại 31 trạm (hình 1), sau đó được bảo quản lạnh và chuyển về phòng thí nghiệm.

Ghi chú: (*): Thời điểm lấy mẫu nghiên cưu là năm 2013 nên chỉ tiêu so sánh là QCVN 10:2008/BTNMT 


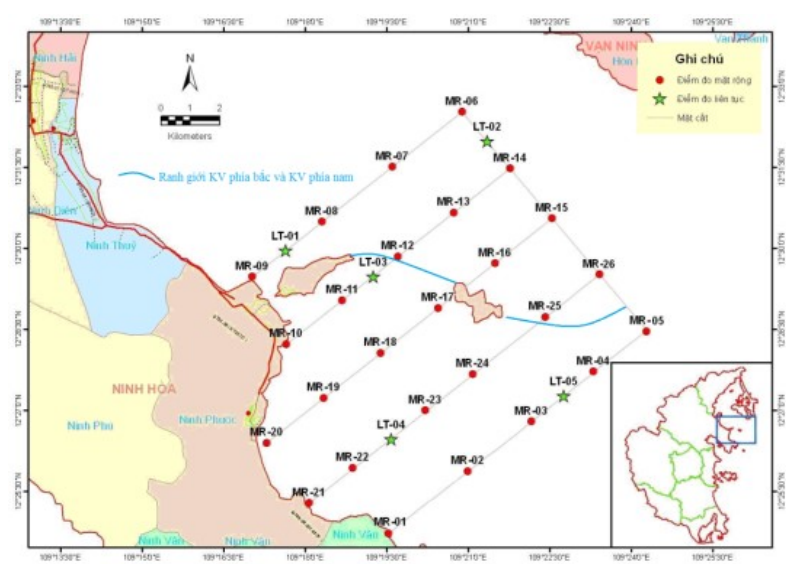

Hình 1. Vị trí các trạm thu mẫu

\subsection{Phương pháp phân tích mẫu}

Các thông số chất lượng nước biển phân tích theo APHA, 2012. Các chỉ tiêu được phân tích bao gồm: tổng chất rắn lơ lửng (TSS), các chất dinh dưỡng (nitrate, ammonia, phosphate, tổng $\mathrm{N}$, tổng $\mathrm{P}$ ).

\subsection{Phương pháp phân tích thống kê}

Phân tích thống kê là giai đoạn cuối cùng của quá trình nghiên cứu thống kê, từ các biểu hiện chung/riêng về lượng nhằm nêu lên một cách tổng hợp bản chất và tính quy luật của các hiện tượng, quá trình hoặc vật chất trong các điều kiện thời gian và không gian cụ thể. Bài báo sử dụng phương pháp Phân tổ thống kê - nghĩa là căn cứ vào một (hay một số) tiêu thức để phân chia khu vực nghiên cứu thành các tổ (vùng nghiên cứu nhỏ hơn) có tính chất khác nhau.

\subsection{Phương pháp tính hệ số rủi ro môi trường}

Đối với hệ sinh thái, hệ số rủi ro RQ được tính như sau:

$$
\mathrm{RQ}=\frac{\mathrm{MEC}(\mathrm{PEC})}{\mathrm{PNEC}}
$$

Trong đó MEC (PEC) là nồng độ đo đạc/tính toán dự báo; PNEC là nồng độ ngưỡng cho phép; RQ là hệ số rủi ro.

Theo hướng dẫn đánh giá hệ số rủi ro của Canada, hệ số RQ có các mức giới hạn sau:

Nếu $\mathrm{RQ}<0,25$ : rất an toàn về mặt môi trường

Nếu $0,25<\mathrm{RQ}<075$ : an toàn về mặt môi trường
Nếu $0,75<\mathrm{RQ}<1$ : có nguy cơ rủi ro môi trường

Nếu RQ > 1: ảnh hưởng tai biến môi trường

Dữ liệu để đánh giá rủi ro được lấy từ kết quả tính toán hiện trạng môi trường khu vực Mỹ Giang - Hòn Đỏ - Bãi Cỏ.

Các giá trị ngưỡng được sử dụng lấy từ nhiều nguồn khác nhau đối với từng thông số, chủ yếu là Tiêu chuẩn quốc gia Việt Nam (các thông số $\mathrm{NH}_{3,4}-\mathrm{N}$, và $\mathrm{TSS}$ ), cụ thể là tiêu chuẩn nước biển ven bờ (QCVN 10:2008/BTNMT). Đối với các thông số không có trong Tiêu chuẩn Việt $\mathrm{Nam}\left(\mathrm{NO}_{3}-\mathrm{N}, \mathrm{PO}_{4}-\mathrm{P}\right)$, các giá trị ngưỡng của nước ngoài và trong khu vực được sử dụng, ví dụ như Tiêu chuẩn đề nghị cho chất lượng nước biển của Đông Nam Á (ASEAN 2003).

\section{Kết luận nghiên cứu và thảo luận}

\subsection{Chất lượng nước biển ven bờ đối với chỉ} tiêu chất dinh dương và độ đục

\subsection{1. Đọt khảo sát tháng 4 năm 2013}

Kết quả phân tích các mẫu nước thu vào tháng 4 năm 2013 được thống kê trong các bảng 1 tầng mặt, tầng đáy, trung bình toàn cột nước (TCN) và theo khu vực (khu vực phía bắc (KVPB), gồm các trạm MR-06, 07, 08, 09, 12, 13, 14, 15, 16, 25, 26, LT-1, 2); khu vực phía nam (KVPN), gồm các trạm MR-01, 02, 03, 04, 05, 10, 11, 17, 18, 19, 20, 21, 22, 23, 24, LT-3, $4,5)$. Ranh giới hai khu vực này đã thể hiện trên hình 1 . Hai khu vực này có địa hình khác nhau và được dự đoán là có điều kiện động lực cũng như các nguồn gây ô nhiễm khác nhau.

Theo kết quả thống kê tại Bảng 1, giữa tầng mặt, tầng đáy và giữa khu vực phía Nam và phía Bắc thay đổi không đáng kể. Đặc biệt, qua đợt khảo sát này cho thấy, hàm lượng TSS tầng mặt cao hơn tầng đáy (đối với cả hai khu vực) nhưng không đáng kể, tầng mặt hàm lượng TSS dao đổng từ 4,4 - 9,5 mg/l, tầng đáy từ 4,3 - 8,5 mg/l. Các thông số còn lại đối với các tầng và khu vực phía Bắc, phía Nam thay đổi không đáng kể. Điều này cho thấy tính ổn định của nước biển khu vực này trong mùa khô. 
Bảng 1. Thống kê kết quả phân tích các thông số chất dinh dương và chất rắn lo lựng (tháng 4 năm 2013, theo tầng và theo khu vực)

\begin{tabular}{|c|c|c|c|c|c|}
\hline & & $\mathrm{NO}_{3}{ }^{-} \mathrm{N}$ & $\mathrm{NH}_{3,4}{ }^{+} \mathrm{N}$ & $\mathrm{PO}_{4}{ }^{3-}$ & TSS \\
\hline & & $\mu \mathrm{g} / 1$ & $\mu \mathrm{g} / 1$ & $\mu \mathrm{g} / 1$ & $\mathrm{mg} / \mathrm{l}$ \\
\hline & TB & 42 & 21,4 & 1,3 & 6,1 \\
\hline KVPB- & CT & 25 & 7,6 & - & 4,5 \\
\hline Mặt & $\mathrm{C} \oplus$ & 78 & 77,5 & 5,6 & 9,5 \\
\hline & $\mathrm{n}$ & 13 & 13 & 13 & 13 \\
\hline & TB & 47 & 28,8 & 3,0 & 5,5 \\
\hline KVPB- & $\mathrm{CT}$ & 26,8 & 6,0 & - & 4,3 \\
\hline Đày & $\mathrm{C}$ & 74,3 & 67,4 & 10,1 & 7,5 \\
\hline & $\mathrm{n}$ & 13 & 13 & 13 & 13 \\
\hline & $\mathrm{TB}$ & 44,7 & 25,1 & 2,1 & 5,8 \\
\hline KVPB- & CT & 24,8 & 6,0 & - & 4,3 \\
\hline TCN & $\mathrm{C} \oplus$ & 78,2 & 77,5 & 10,1 & 9,5 \\
\hline & $\mathrm{n}$ & 26 & 26 & 26 & 26 \\
\hline & & $\mathrm{NO}_{3}{ }^{-} \mathrm{N}$ & $\mathrm{NH}_{3,4}{ }^{+} \mathrm{N}$ & $\begin{array}{c}\mathrm{PO}_{4}{ }^{3-} \\
\mathrm{P}\end{array}$ & TSS \\
\hline & & $\mu \mathrm{g} / \mathrm{l}$ & $\mu \mathrm{g} / 1$ & $\mu \mathrm{g} / 1$ & $\mathrm{mg} / \mathrm{l}$ \\
\hline & TB & 40,6 & 27,0 & 3,2 & 5,9 \\
\hline KVPN- & CT & 24,7 & 9,6 & - & 4,4 \\
\hline Mặt & $\mathrm{C} \oplus$ & 56,2 & 74,9 & 8,5 & 9,2 \\
\hline & $\mathrm{n}$ & 18 & 18 & 18 & 18 \\
\hline & TB & 39,2 & 24,7 & 2,8 & 5,7 \\
\hline KVPN- & CT & 22,5 & 9,2 & - & 4,4 \\
\hline Đày & $\mathrm{C} \oplus$ & 58,7 & 65,3 & 9,3 & 8,5 \\
\hline & $\mathrm{n}$ & 18 & 18 & 18 & 18 \\
\hline & TB & 39,9 & 25,9 & 3,0 & 5,8 \\
\hline KVPN- & $\mathrm{CT}$ & 22,5 & 9,2 & - & 4,4 \\
\hline $\mathrm{TCN}$ & $\mathrm{C}$ & 58,7 & 74,9 & 9,3 & 9,2 \\
\hline & $\mathrm{n}$ & 36 & 36 & 36 & 36 \\
\hline
\end{tabular}

Ghi chú: TB: trung bìn, CT: cưc tiểu, CĐ: cực đại, n: số lương mẫu.

\subsection{2. Đợt khảo sát tháng 10 năm 2013}

Kết quả phân tích các mẫu nước thu vào tháng 10 năm 2013 được thống kê trong bảng 2 theo tầng mặt, tầng đáy, trung bình toàn cột nước và theo hai khu vực (như phần trên).

Bảng 2. Thống kê kết quả phân tích các thông số chất dinh dương và chất rắn lo lửng (tháng 10 năm 2013, theo tầng và theo khu vục)

\begin{tabular}{|c|c|c|c|c|c|}
\hline $\begin{array}{c}\text { Khu vực } \\
\text { Tầng }\end{array}$ & $\begin{array}{l}\text { Giá } \\
\text { trị }\end{array}$ & $\begin{array}{c}\mathrm{NO}_{3}-\mathrm{N} \\
\mu \mathrm{g} / \mathrm{l}\end{array}$ & $\begin{array}{c}\mathrm{NH}_{3,4-\mathrm{N}} \\
\mu \mathrm{g} / \mathrm{l}\end{array}$ & $\begin{array}{c}\mathrm{PO}_{4}-\mathrm{P} \\
\mu \mathrm{g} / \mathrm{l}\end{array}$ & $\begin{array}{l}\mathrm{TSS} \\
\mathrm{mg} / \mathrm{l}\end{array}$ \\
\hline \multirow{4}{*}{$\begin{array}{l}\text { KVPB- } \\
\text { Mặt }\end{array}$} & TB & 48 & 31,2 & 5,7 & 9,2 \\
\hline & $\mathrm{CT}$ & 30 & 12,8 & 0,8 & 4,5 \\
\hline & $\mathrm{C} \oplus$ & 64 & 66,3 & 14,9 & 14,4 \\
\hline & $\mathrm{n}$ & 13 & 13 & 13 & 13,0 \\
\hline \multirow{4}{*}{$\begin{array}{c}\text { KVPB- } \\
\text { Đáy }\end{array}$} & TB & 57 & 33,3 & 7,5 & 6,3 \\
\hline & $\mathrm{CT}$ & 41 & 11,2 & 2,8 & 4,5 \\
\hline & $\mathrm{C} \oplus$ & 78 & 62,0 & 15,7 & 10,1 \\
\hline & $\mathrm{n}$ & 13 & 13 & 13 & 13 \\
\hline \multirow{4}{*}{$\begin{array}{c}\text { KVPB- } \\
\text { TCN }\end{array}$} & TB & 52 & 32,2 & 6,6 & 7,8 \\
\hline & $\mathrm{CT}$ & 30 & 11,2 & 0,8 & 4,5 \\
\hline & $\mathrm{C} \bigoplus$ & 78 & 66,3 & 15,7 & 14,4 \\
\hline & $\mathrm{n}$ & 26 & 26,0 & 26,0 & 26 \\
\hline Khu vực & Giá & $\mathrm{NO}_{3}-\mathrm{N}$ & $\mathrm{NH}_{3,4}-\mathrm{N}$ & $\mathrm{PO}_{4}-\mathrm{P}$ & TSS \\
\hline Tầng & $\operatorname{trị}$ & $\mu \mathrm{g} / 1$ & $\mu \mathrm{g} / 1$ & $\mu \mathrm{g} / \mathrm{l}$ & $\mathrm{mg} / \mathrm{l}$ \\
\hline \multirow{4}{*}{$\begin{array}{c}\text { KVPN- } \\
\text { Mặt }\end{array}$} & TB & 48 & 27,6 & 6,8 & 9,3 \\
\hline & $\mathrm{CT}$ & 30 & 10,9 & 0,8 & 4,1 \\
\hline & $\mathrm{C} \oplus$ & 65 & 60,1 & 16,6 & 17,0 \\
\hline & $\mathrm{n}$ & 18 & 18 & 18 & 18 \\
\hline \multirow{4}{*}{$\begin{array}{l}\text { KVPN- } \\
\text { Đáy }\end{array}$} & $\mathrm{TB}$ & 50 & 28,7 & 8,5 & 6,8 \\
\hline & $\mathrm{CT}$ & 37 & 9,3 & 4,0 & 4,1 \\
\hline & $\mathrm{CÐ}$ & 71 & 68,6 & 15,4 & 16,0 \\
\hline & $\mathrm{n}$ & 18 & 18 & 18 & 18 \\
\hline \multirow{4}{*}{$\begin{array}{c}\text { KVPN- } \\
\text { TCN }\end{array}$} & $\mathrm{TB}$ & 49 & 28,2 & 7,6 & 8,0 \\
\hline & $\mathrm{CT}$ & 30 & 9,3 & 0,8 & 4,1 \\
\hline & $\mathrm{C} Ð$ & 71 & 68,6 & 16,6 & 17,0 \\
\hline & $\mathrm{n}$ & 36 & 36 & 36 & 36 \\
\hline
\end{tabular}

Ghi chú: TB: trung bình, CT: cưc tiểu, CĐ: cưc đại, n: số lượng mẫu. 
Các giá trị thống kê trong bảng 2 cho thấy là vào mùa mưa nước biển hai khu vực phía Bắc và phía nam cũng có giá trị nồng độ của TSS và các chất dinh dưỡng không khác nhau nhiều.

3.1.3. Chất lượng môi trường nước biển khu vưc nghiên cưu

Bảng 3. Giá trị tối đa cho phép của một số chi tiêu chất lượng nước biển ven bò̀

\begin{tabular}{ccccccc}
\hline Thông số & Đơn vị & \multicolumn{2}{c}{ Giá trị trung bình mùa khô } & \multicolumn{2}{c}{ Giá trị trung bình mùa mưa } & QCVN 10:2008/BTNMT(cột \\
& & KVPB & KVPN & KVPB & KVPN & nước nuôi trồng thủy sản) \\
\hline $\mathrm{NH}_{3,4}-\mathrm{N}$ & $\mathrm{mg} / 1$ & 0,0251 & 0,0252 & 0,0322 & 0,0282 & 0,1 \\
$\mathrm{NO}_{3}-\mathrm{N}^{(*)}$ & $\mathrm{mg} / 1$ & 0,0445 & 0,0399 & 0,0525 & 0,0490 & $0,06^{(*)}$ \\
$\mathrm{TSS}$ & $\mathrm{mg} / 1$ & 5,8 & 5,8 & 7,8 & 8,0 & 50 \\
$\mathrm{PO}_{4}-\mathrm{P}$ & $\mathrm{mg} / 1$ & 0,0022 & 0,0030 & 0,0066 & 0,0077 & $0,015^{(*)}$ \\
\hline
\end{tabular}

Ghi chú: (*) Giá trị theo quy chuẩn ASEAN 2003.

Nhìn chung, các giá trị phân tích cho thấy nồng độ $\mathrm{NH}_{3,4} \mathrm{~N}, \mathrm{PO}_{4} \mathrm{P}$, TSS thấp hơn nhiều so với giới hạn cho phép ở các tầng và trung bình toàn khu vực nghiên cứu. Một số giá trị nồng nitrate cao hơn 0,060 mg/l (Theo Tiêu chuẩn Nước biển ven bờ ASEAN, Canadian Council of Ministers of the Environment, 2003a) gặp ở 3/62 mẫu tại các trạm MR09 và MR15 vào mùa khô; 9/62 mẫu được phân tích (tại các trạm MR06, MR12, MR13, MR14, MR23 và MR24 (với các nồng độ dao động từ 0,061 đến $0,076 \mathrm{mg} / \mathrm{l}$ ) vào mùa mưa. Tuy nhiên, tính trung bình trên toàn khu vực thì nồng độ nitrate vẫn nằm trong giới hạn cho phép. Nguyên nhân có thể do khu vực

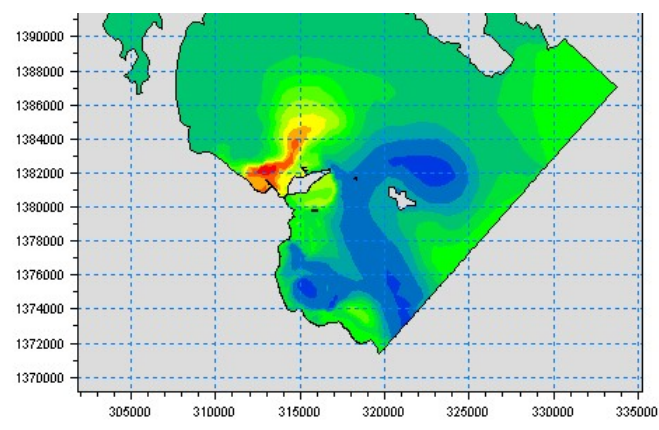

Hình 2. Hệ số rủi ro $\mathrm{NH}_{4}$ lúc triều lên
Chất lượng môi trường nước biển được đánh giá chủ yếu theo Quy chuẩn Nước biển ven bờ (QCVN 10:2008/BTNMT), cột nước nuôi trồng thủy sản. Mức tới hạn của các chỉ tiêu liên quan được giới thiệu trong bảng 3 . nghiên cứu đã bị ảnh hưởng bởi sự các vuông nuôi thủy hải sản từ khu vực nuôi trồng Hòn Đỏ.

\section{2. Đánh giá rủi ro khu vục nghiên cúu}

3.2.1. So sánh ảnh hưởng của triều trong việc tính toán hệ số rủi ro

Trong tính toán hệ số rủi ro tại khu vực nghiên cứu, dữ liệu sẽ được lấy ở những thời điểm khác nhau để tính toán rủi ro, bao gồm giữa lúc triều lên và triều xuống trong cùng một ngày để xem xét giá trị của hệ số rủi ro khác biệt như thế nào. Tuy nhiên, qua việc tính toán hệ số rủi ro giữa lúc triều xuống và triều lên trong cùng một ngày, kết quả cho thấy không có sự khác biệt về giá trị (hình 2 và hình 3 ).

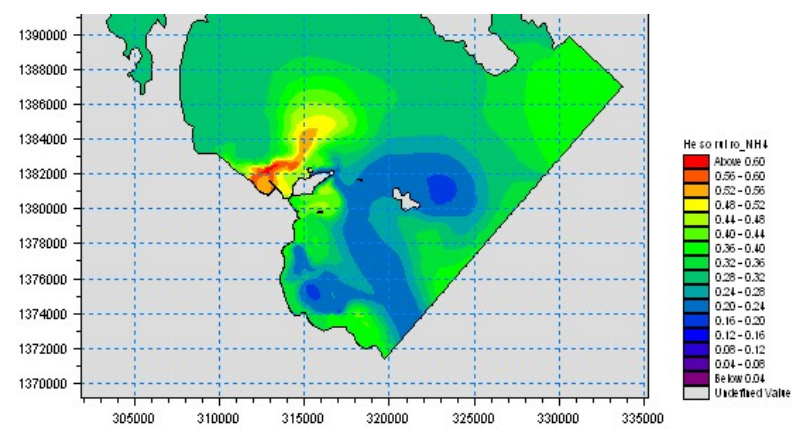

Hình 3. Hệ số rủi ro $\mathrm{NH}_{4}$ lúc triều xuống 


\section{BÀI BÁO KHOA HỌC}

Như vậy, hệ số rủi ro sẽ được tính toán vào những thời điểm khác nhau như sau 1 ngày, 3 ngày, 7 ngày và 15 ngày tính toán trong toàn khu vực nghiên cứu vào lúc triều lên. Hệ số rủi ro được tính toán trên toàn không gian vùng nghiên cứu theo các thời điểm khác nhau, từ đó đưa ra RQ lớn nhất tại từng thời điểm để đánh giá mức độ rủi ro.

\subsubsection{Mức độ rủi ro vào mùa khô}

Như đã trình bày ở trên, hầu hết các thông số đều có giá trị nằm trong giới hạn cho phép của QVCN 10:2008/BTNMT và tiêu chuẩn ASEAN 2003 nên giá trị các hệ số rủi ro RQ của các thông số nghiên cứu về chất lượng dinh dưỡng $\left(\mathrm{NH}_{3,4}-\mathrm{N}, \mathrm{NO}_{3}-\mathrm{N}, \mathrm{PO}_{4}-\mathrm{P}\right)$ và chất rắn lơ lửng (TSS) đều nhỏ hơn 1

Bảng 4. Kết quả tính $R Q$ của chất dinh duỡng và chất rắn lơ lửng khu vực nghiên cứu mùa khô so với tiêu chuẩn chất lượng nước biển ASEAN (2003) và QCVN 10:2008/BTNMT

\begin{tabular}{|c|c|c|c|c|l|}
\hline \multirow{2}{*}{$\begin{array}{c}\text { Thông } \\
\text { số }\end{array}$} & \multicolumn{4}{|c|}{ RQmax } & \multirow{2}{*}{ Đánh giá } \\
\cline { 2 - 5 } & Sau 1 ngày & Sau 3 ngày & Sau 7 ngày & Sau 15 ngày & \\
\hline $\mathrm{NO}_{3}-\mathrm{N}$ & 0,80 & 0,72 & 0,70 & 0,70 & Có nguy cơ rủi ro môi trường \\
\hline $\mathrm{PO}_{4}-\mathrm{P}$ & 0,25 & 0,17 & 0,16 & 0,15 & Rất an toàn về mặt môi trường \\
\hline $\begin{array}{c}\mathrm{NH}_{3}- \\
\mathrm{N}\end{array}$ & 0,40 & 0,31 & 0,31 & 0,31 & An toàn về mặt môi trường \\
\hline TSS & 0,14 & 0,12 & 0,12 & 0,12 & Rất an toàn về mặt môi trường \\
\hline
\end{tabular}

Xét về không gian, hệ số RQ của các chất tại khu vực ven bờ sau các thời điểm tính toán cho thấy RQ có giá trị khá nhỏ. Nồng độ các chất đã bị dòng chảy khuếch tán và đưa vào sâu trong vịnh hoặc ra ngoài khơi. Vì vậy, tuy hệ số RQ của nitrat giao động trong khoảng 0,75 - 1
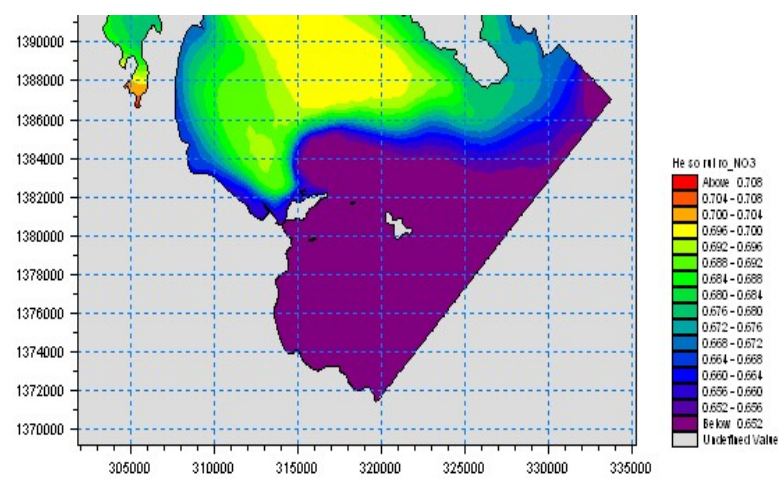

Hình 4. Hệ số rủi ro $\mathrm{NO}_{3}-\mathrm{N}$ hiện trạng tháng 4 sau 15 ngày tính toán nhưng giá trị này nằm khá xa khu vực ven bờ, chủ yếu ở phía Đông Bắc và phía Bắc của khu vực nghiên cứu. Nhìn chung, môi trường nước biển ven bờ khu vực nghiên cứu còn khá sạch và chưa có dấu hiệu bị ô nhiễm.

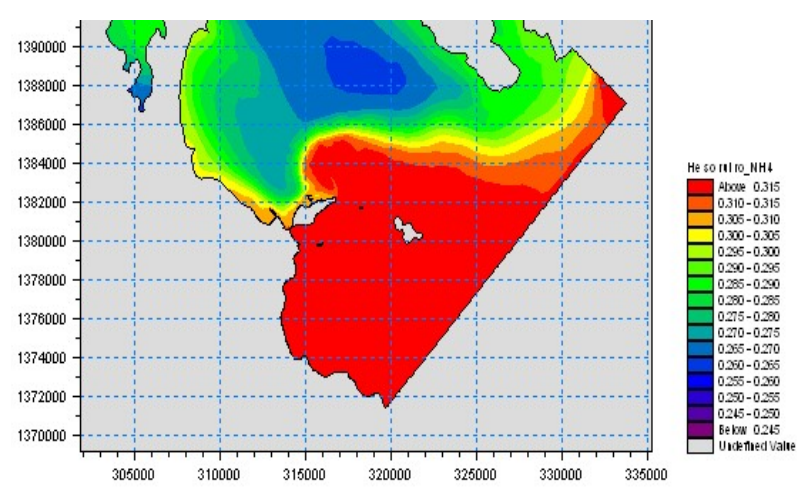

Hình 5. Hệ số rủi ro $\mathrm{NH}_{3,4-\mathrm{N}}$ hiện trạng tháng 4 sau 15 ngày tính toán 


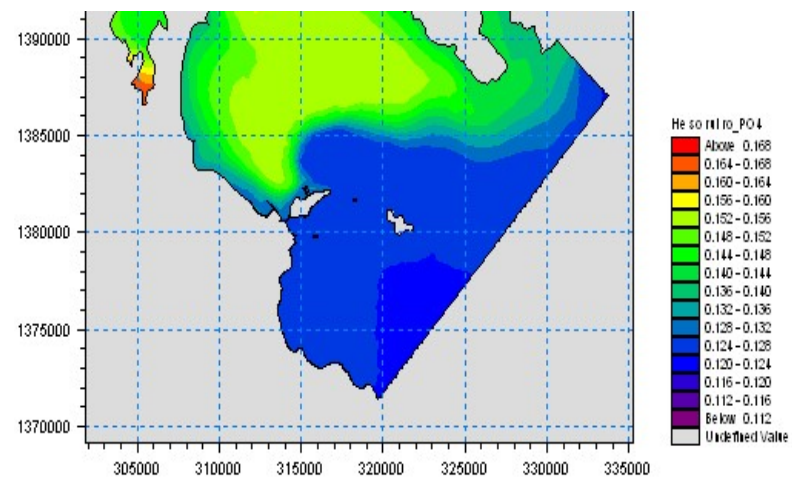

Hình 6. Hệ số rủi ro $\mathrm{PO}_{4}-\mathrm{P}$ hiện trạng tháng 4 sau 15 ngày tính toán

\subsubsection{Mức độ rủi ro vào mùa mua}

Kết quả tính toán $R Q$ vào tháng 10 các chất dinh dưỡng và chất rắn lơ lửng đều có giá trị lớn hơn so với tháng 4 , đồng thời hệ số RQmax cũng giảm dần theo thời gian tính toán, điều này là do chế độ sóng, dòng chảy, thủy triều,... khuếch tán và vận chuyển nồng độ các chất loãng đi và ra xa khu vực xả thải.

Bảng 5. Kết quả tính $R Q$ của chất dinh duõng và chất rắn lo lửng khu vực nghiên cứu mùa mura so với tiêu chuẩn chất lượng nước biển ASEAN (2003) và QCVN 10:2008/BTNMT

\begin{tabular}{|c|c|c|c|c|c|}
\hline \multirow[b]{2}{*}{$\begin{array}{c}\text { Thông } \\
\text { số }\end{array}$} & \multicolumn{4}{|c|}{ RQmax } & \multirow[b]{2}{*}{ Đánh giá } \\
\hline & $\begin{array}{l}\text { sau } 1 \\
\text { ngày }\end{array}$ & $\begin{array}{l}\text { sau } 3 \\
\text { ngày }\end{array}$ & $\begin{array}{c}\text { sau } \\
7 \\
\text { ngày }\end{array}$ & $\begin{array}{c}\text { sau } \\
15 \\
\text { ngày }\end{array}$ & \\
\hline $\mathrm{NO}_{3}-\mathrm{N}$ & 0,96 & 0,92 & 0,87 & 0,85 & $\begin{array}{l}\text { có nguy cơ rủi } \\
\text { ro môi trường }\end{array}$ \\
\hline $\mathrm{PO}_{4}-\mathrm{P}$ & 0,68 & 0,65 & 0,54 & 0,48 & $\begin{array}{l}\text { an toàn về mặt } \\
\text { môi trường }\end{array}$ \\
\hline $\begin{array}{l}\mathrm{NH}_{3}- \\
\mathrm{N}\end{array}$ & 0,60 & 0,55 & 0,4 & 0,37 & $\begin{array}{l}\text { an toàn về mặt } \\
\text { môi trường }\end{array}$ \\
\hline TSS & 0,20 & 0,20 & 0,18 & 0,18 & $\begin{array}{l}\text { rất an toàn về } \\
\text { mặt môi trường }\end{array}$ \\
\hline
\end{tabular}

Giá trị $\mathrm{NH}_{3,4}-\mathrm{N}$ tính toán được trong tháng 10 theo các kịch bản nhỏ hơn khá nhiều so với giá trị ngưỡng. Do đó chỉ số RQ đối với $\mathrm{NH}_{3}-\mathrm{N}$ so với tiêu chuẩn Việt Nam là khá nhỏ. Vì vậy, hệ số $\mathrm{RQ}$ của $\mathrm{NH}_{3,4}-\mathrm{N}$ an toàn về mặt môi trường sinh thái.

Chỉ số RQ của Photphat cũng khá nhỏ, RQ

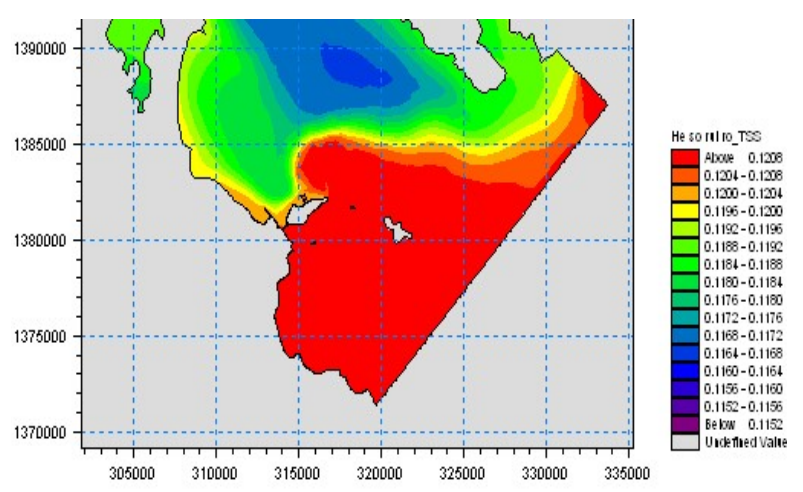

Hình 7. Hệ số rủi ro TSS hiện trạng tháng 4 sau 15 ngày tính toán

lớn nhất trong các kịch bản tính toán chỉ bẳng 0,68 , điều này cho thấy Photphat chưa bị ô nhiễm và có thể xem như an toàn về mặt môi trường sinh thái, Chỉ số RQ của Photphat giảm dần theo thời gian tính toán và có giá trị cao tại khu vực ven bờ về phía Nam khu vực nghiên cứu.

Trong qui chuẩn Việt Nam không có quy định nitrat nên thông số này sẽ được tính theo tiêu chuẩn nước biển ven bờ của ASEAN (2003).

Chỉ số Nitrat có RQmax tuy nhỏ hơn 1 nhưng cũng gần bằng $1, \mathrm{RQ}$ lớn nhất sau 1 ngày tính toán, điều này cho thấy nguy cơ ô nhiễm nitrat trong khu vực nghiên cứu là rất đáng quan tâm. Đồng thời, ở tháng 10 này thì RQ lớn nhất lại nằm tại khu vực ven bờ và nồng độ giảm không đáng kể theo thời gian. Vì vậy, khả năng rủi ro của Nitrat tại khu vực nghiên cứu có nguy cơ cao và cần được quan tâm về mặt môi trường sinh thái.

Kết quả tính toán hệ số rủi ro TSS vào mùa mưa rất nhỏ, hệ số RQ lớn nhất cũng chỉ 0,2 , cho thấy TSS không bị ô nhiễm tại khu vực nghiên cứu và rất an toàn về môi trường. Hệ số rủi ro của TSS vào mùa mưa không chênh lệch nhiều so với mùa khô. Theo thời gian hệ số rủi ro giảm dần nhưng cũng không đáng kể.

Xét về không gian, hệ số RQ của các chất tại khu vực nghiên cứu sau các thời điểm tính toán cho thấy RQ có giá trị khá lớn tại khu vực ven bờ và xung quanh hòn Mỹ Giang. Nồng độ các chất đã bị dòng chảy khuếch tán và đưa vào sâu trong vịnh hoặc ra ngoài khơi theo thời gian, Kết quả hệ số rủi ro giữa các kịch bản không khác nhau nhiều về mặt giá trị và không gian. 


\section{BÀI BÁO KHOA HỌC}

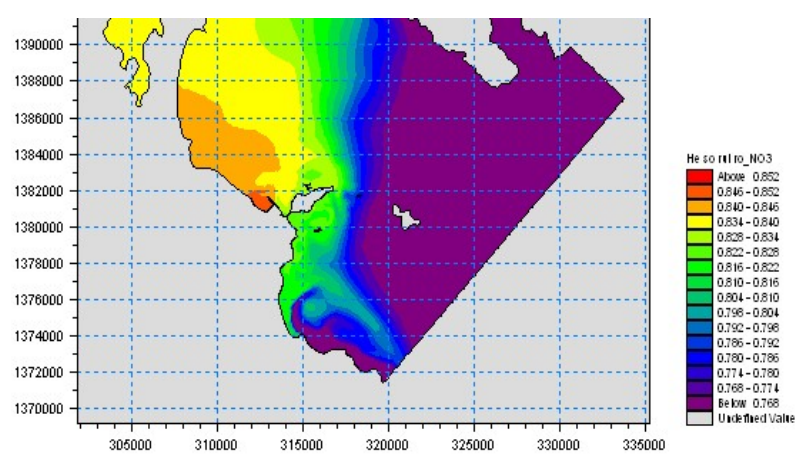

Hình 8. Hệ số rủi ro $\mathrm{NO}_{3}-\mathrm{N}$ hiện trạng tháng 10 sau 15 ngày tính toán

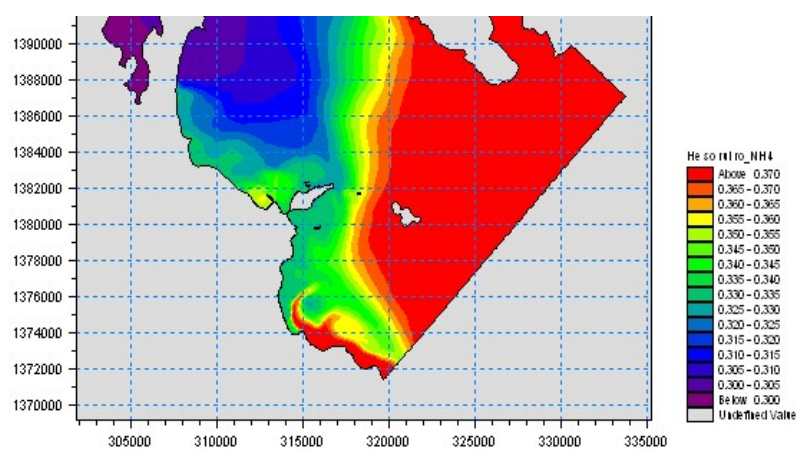

Hình 10. Hệ số rủi ro $\mathrm{PO}_{4}-\mathrm{P}$ hiện trạng tháng 10 sau 15 ngày tính toán

\section{Kết luận}

So sánh kết quả chất lượng nước với những kết quả nghiên cứu trong vùng Vân Phong - Bến Gỏi trước đây cho thấy giá trị các thông số chất lượng nước biển trong khu vực nghiên cứu nhìn chung các thông số nằm trong xu hướng chung của cả vùng như: $\mathrm{NO}_{3} \mathrm{~N}, \mathrm{NH}_{3,4} \mathrm{~N}$, riêng đối với chỉ tiêu $\mathrm{PO}_{4}-\mathrm{P}$ thấp hơn nhiều so với giá trị chung. Cụ thể, theo Lê Thị Vinh, 2008, 2009 và 2012, chất lượng nước biển vùng Vân Phong Bến Gỏi biểu hiện qua thông số tổng chất rắn lơ lửng (TSS) của nước ít biến động (pH: 7,80-

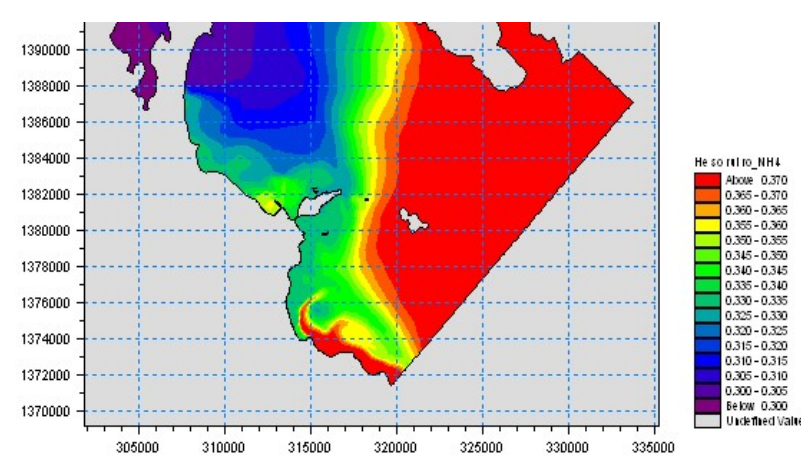

Hình 9. Hệ số rủi ro $\mathrm{NH}_{3,4-\mathrm{N}}$ hiện trạng tháng 10 sau 15 ngày tính toán

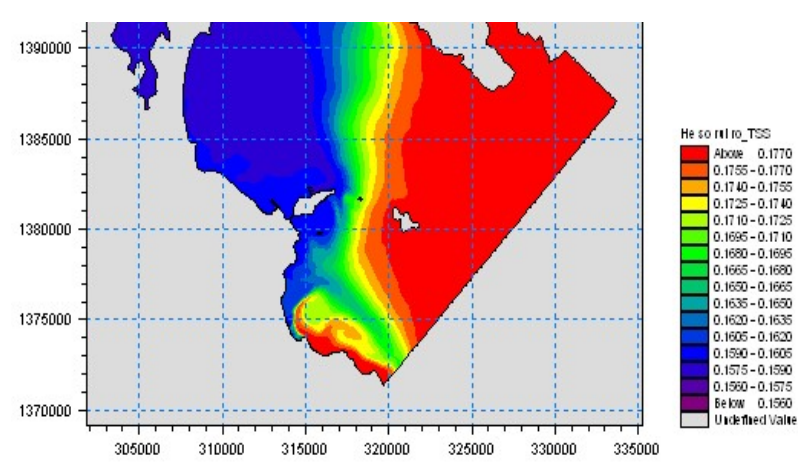

Hình 11. Hệ số rủi ro TSS hiện trạng tháng 10 sau 15 ngày tính toán

8,22; TSS: 19,0-36,4 mg/l), nồng độ các muối nitrite $(0-8,7 \mu \mathrm{gN} / 1)$, ammonia $(0-76 \mu \mathrm{gN} / 1)$ khá thấp, phosphate $(5,3-16,6 \mu \mathrm{gP} / 1)$ ở mức trung bình [4]. Kết quả tính toán cho thấy môi trường nước biển tại khu vực nghiên cứu chưa có dấu hiệu ô nhiễm, tuy nhiên, cần chú ý đến việc xả thải các chất dinh dưỡng vì nguy cơ ô nhiễm nitrat trong vùng nghiên cứu có khả năng xảy ra cao; các chỉ số khác như RQ của Photphat và Amoni, chất rắn lơ lửng là không đáng kể, có thể xem như an toàn về mặt môi trường sinh thái. 


\title{
Tài liệu tham khảo
}

1. APHA (2012), Standard Methods for the Analysis of Water and WasteWater. 22nd Edition

2. Bộ Tài Nguyên và Môi Trường (2008), Qui chuẩn Kĩ thuật quốc gia QCVN 10:2008/BTNMT: Chất lương nước biển ven bò̀.

3. Canadian Council of Ministers of the Environment, (2003a), Marine water Quality Criteria for The ASEAN Region - Online Publication.

4. Lê Thị Vinh (2012), Hàm lương các kim loại nặng trong môi trường vịnh Vân Phong - Bến Gỏi, Khánh Hòa. Tạp chí Khoa học và Công nghệ biển. 3(T.12). Tr 12-23.

5. Tổng cục môi trường, cục kiểm soát ô nhiễm (2010), Xây dụng bộ tiêu chí khoanh vùng kiểm soát ô nhiếm môi trường nước biển ven bò̀, tr.21.

\section{EVALUATE TO THE RISK RATIO IN COASTAL AREA OF MY GIANG - HON DO - BAI CO IN NINH PHUOC COMMUNE, NINH HOA TOWN, KHANH HOA PROVINCE Nguyen Tram Anh', Nguyen Ky Phung²}

\begin{abstract}
Environmental risk assessment by using risk quotient parameter is the quantification of the environmental damaging ability of human factors, therefore it can be minimized or prevented environmental risks that may occur in studied area for optimize the cost of treatment or recuperation for damage. An assessment of the coastal water environment risk in the My GiangHon Do-Bai Co area can identify potential actors through the sampled and analyzed sea water quality parameters - which were within the limits of QCVN 10: 2008/BTNMT as: nutrients $\left(\mathrm{NH}_{3,4}-\mathrm{N}, \mathrm{NO}_{3}-\mathrm{N}, \mathrm{PO}_{4}-\mathrm{P}\right)$ and suspended solids (TSS). The calculated results of risk quotient of nutrients $\left(\mathrm{NH}_{3,4}-\mathrm{N}\right)$; $\left(\mathrm{NO}_{3}-\mathrm{N}\right)$ và $\left(\mathrm{PO}_{4}-\mathrm{P}\right)$ at the time of sampling and after translating 1 to 15 days respectively ranging from (0.45-0.33); (0.80-0.70) and (0.27-0.14); suspended solids (TSS) were (0.14-0.12) indicating that at the time of the survey, the study area remained within the safe limits of the environment.
\end{abstract}

Keywords: Coastal water quality, risk quotient (RQ), My Giang - Hon Do - Bai Co. 